\title{
Journalism from the peripheries. From the Swiss-Italian media system to other local dimensions. ECREA 2018 special panel report
}

\author{
Joy Jenkins, University of Oxford, Reuters Institute for the Study of Journalism \\ joy.jenkins@politics.ox.ac.uk
}

\section{Note}

Invited report for the Thematic Section on ECREA 2018 devoted to the $7^{\text {th }}$ European Communication Conference of the European Communication and Research Association (ECREA), held in Lugano from October $31^{\text {st }}$ to November $3^{\text {rd }}, 2018$.

The fate of local journalism has become a prominent discussion point among academics, industry insiders, news managers, and journalists alike. Continued declines in subscription and print advertising revenues, coupled with the challenges of developing sustainable business models online, have prompted headlines ranging from "The death of the local newspaper" in the BBC (Business Daily, 2019) to "Read all about it? How local papers' decline is starving communities of news" in the Guardian (Waterson, 2019) to "Local newspapers have already been gutted. There's nothing left to cut" in the Washington Post (Cavendish, 2019).

Research reports have identified trends that are both concerning, such as the growth of "news deserts" (Abernathy, 2018) and a lack of originally produced, locally focused information addressing critical information needs (Napoli, Weber, McCullough, \& Wang, 2018) in communities around the U.S., and reassuring, such as the rise of collaborative efforts among local news organizations (Jenkins \& Graves, 2019; Stonbely, 2017). This attention reinforces the important roles local news organizations play in their communities, serving as sources of reliable, accurate information; local watchdogs; and reflections of communities to themselves and the world (Harte, Williams, \& Turner, 2017), as well as their broader functions in democratic societies, including providing public affairs coverage that other media build upon and reuse (Nielsen, 2015) and spurring citizen engagement (Hayes \& Lawless, 2018).

As a concept, "local journalism" can be understood in a variety of ways, from community journalism, often encapsulated in the hometown newspaper (Reader \& Hatcher, 2011), to "hyperlocal" news provision via blogs, social media, and other platforms (Harte, Howells, \& Williams, 2019) to local media as providers of "geo-social" news across spaces and platforms (Hess, 2013). These approaches are present in countries around the world, but they may take different forms and their producers may face different challenges and opportunities depending on the media system, social context, political environment, and language area in which they operate.

\section{Topics and participants}

Inspired by the ECREA 2018 theme "Centres and Peripheries" and the conference setting in the Italian-speaking region of Switzerland, the panel "Journalism from the peripheries. From the Swiss-Italian media system to other local dimensions" explored how changing dynamics in the contemporary news environment affect local news provision in less-examined or peripheral - geographic areas. Joining moderator Philip Di Salvo, post-doctoral researcher at Università della Svizzera italiana's Institute of Media and Journalism, panelists discussed forces shaping how lo- 
cal media at the peripheries of contemporary journalism maximize their distinctive positions to produce and distribute news that effectively represents and serves their communities.

The first portion of the panel explored the distinguishing characteristics of the Swiss media system from both macro and micro perspectives, including the influence of media policy on innovation among Swiss media, idiosyncrasies of the Swiss media system, and the function of public service broadcasting. In the first presentation, Colin Porlezza, senior lecturer and researcher at City, University of London, offered an introduction to the Swiss media landscape, asking the provocative question, "Are Swiss media losing their edge?" Media concentration in Switzerland remains, as Porlezza described, "alarmingly high," particularly when situated against the continuing financial challenges facing legacy media. As a media environment, Switzerland is characterized by: 1) small markets and significant linguistic and cultural diversity; 2) limited resources, including investments of advertising expenditures per capita; and 3) the significant influence of foreign media, including the U.K., Italy, France, and Germany, what Porlezza termed the "next-door giants phenomenon." This influence means that political, economic, technological, and other shifts occurring in these markets and affecting foreign news producers can also significantly shape the provision and content of news for Swiss audiences. Three media organizations dominate the Swiss print media market: Ringier, Tamedia and NZZ Group. Within these groups, there has been rapid growth in centralized editorial offices; mergers of regional newspapers, websites, and radio and TV stations; and the creation of journalistic networks resulting from buyouts, sales, and joint ventures. Media companies may argue that this strategy concentrates expertise in one place. It also means that journalistic diversity, in terms of where, how, and for whom content is produced as well as the overall diversity of content is declining, according to Porlezza. Studies by the Research Institute for the Public
Sphere and Society at the University of $\mathrm{Zu}$ rich confirm this trend.

Continued efforts at ownership concentration, which affect the print as well as online and advertising markets, raise concerns about potential abuses by powerful investors with political interests. Considering all of these factors, as well as the dominance of tech platforms in the advertising market, Porlezza called for interventions in the form of media policy, such as a recent law drafted by the Federal Council calling for direct media promotion for online media, financial support for journalism training, media self-regulation, and infrastructures and projects focused on innovation in online media.

In his talk "The Swiss media system and its idiosyncrasies", Matthew Hibberd, director of the Institute of Media and Journalism at the USI Università della Svizzera italiana, also addressed particularities of the Swiss media system, noting that although it features the same democratic-corporate model as the "next-door giants," it also offers more press freedom, contributing to the development of a socially responsible media system. There is, therefore, value in examining the details of media work in this region, exploring "what's in the shadows," as Hibberd described, and illuminating connections between seemingly insignificant events to better understand this news environment and potentially others like it.

Massimiliano Herber brought a journalist's perspective to the discussion, addressing the role of public service broadcasting in the Italian-speaking part of Switzerland in his presentation entitled "The role of public service broadcasting in the Italian speaking part of Switzerland". Herber is a regional director with RSI Radiotelevisione Svizzera, which includes a website, two television networks, and three radio channels serving the region's 400,000 residents. Herber, like Porlezza, addressed the drastic changes the Swiss media market has seen over the last few decades. For example, in 1990, the Ticino region was served by six newspapers, a political magazine, a public broadcaster, and a radio station; today, the area is served 
by three newspapers and two Sunday papers, multiple radio channels, and eight news websites (and growing). To cover a region that features distinct language and geographic boundaries and high levels of political autonomy, RSI has focused on offering in-depth reporting from around the country as well as meaningful and impactful local news. Herber reinforced that RSI's journalists live and work in the communities they cover, which places even more responsibility on them to remain vigilant in their reporting, consider how national and international news events affect local readers, and examine the interconnections between the local and global in a changing world. Ultimately, he said, the "human factor" is key, and RSI journalists focus not just on reporting the news but also on telling human stories.

The final two presentations took a broader look at the local-news ecosystem. In her talk "The digital transition of local news", Joy Jenkins, postdoctoral research fellow at the Reuters Institute for the Study of Journalism at the University of Oxford, shared findings from interviews with editorial and commercial staff members at eight local and regional newspapers in four countries (Finland, France, Germany, and the U.K.). She and co-author Rasmus Kleis Nielsen found that these news organizations are pursuing three approaches to producing and monetizing local news in the digital age: the search for national scale, regional breadth, or local depth. The national scale approach, which was evident among national publishers in the U.K., focuses on pursuing economies of scale through acquiring diverse portfolios to draw the largest possible audience, monetized through advertising. These companies feature centralized newsrooms producing online content that can be distributed across multiple newspapers and adapted to local markets, as well as a shared digital culture in which newsrooms receive training in new digital strategies and can participate in company-wide editorial initiatives. The regional breadth approach also emphasizes economies of scale but with a more focused portfolio of editorial offerings for a particular region.
Purveyors of this strategy, such as regional publishers in France, Germany, and Finland, aim to leverage their distinct market positions in particular areas to derive revenues through paid online content, events, services, and e-commerce. These companies also feature centralized approaches to content production and advertising sales, in addition to solutions-focused digital teams to help local newsrooms develop new tools for producing and distributing content. Lastly, the local depth approach, pursued by individual local titles and by titles owned by smaller parent companies across the sample, seeks to report on - and draw revenues from - smaller geographic areas. They rely on paid content models and diverse business models but often with less-developed infrastructures for digital production. Overall, rather than focusing solely on cutting costs to remain profitable in the face of declining legacy revenues, these news organizations are investing in new digital offerings and business models designed to engage audiences and ensure their sustainability.

Using the topic "Sustaining media on the edge", Clare Cook, senior lecturer in print and online journalism in the School of Journalism, Media and Performance at the University of Central Lancashire, also discussed changing business models for local news, focusing specifically on European digital-first and digital-only hyperlocals. These outlets have emerged in the context of growing "news gaps" at the local level, which manifest as "local" content that is produced in far-flung locations or as a complete lack of local coverage. In response to these concerns - and aided by low entry barriers in the online space - hyperlocals have developed from the grassroots level in the form of blogs, social media sites, and other platforms. Although multiple studies and projects have explored hyperlocal media (e.g., Van Kerkhoven \& Bakker, 2014; Kurpius et al., 2010; Metzgar et al., 2011; Nygren et al., 2017), less is known about their commercial models, practices, and experiences. In response, Cook and her colleagues have drawn from business ecosystems theory to address the business pressures facing hyperlocals and 
the conditions in which they compete and evolve. This research finds that hyperlocals sustain themselves through forging relationships with other media, businesses, advertisers, and communities in their local environments, a process that results in cooperation, competition, and co-evolution in a dynamic system. Based on case studies of 35 hyperlocals across the U.K., the Netherlands, France, Belgium, and Sweden, the researchers created a taxonomy of three business models: viable (sites fulfilling a demand or perceived need for content by the audience), sustainable (sites able to sustain a flow of content over time and that are likely to draw revenues), and resilient (sites that can sustain a flow of content and make a profit, or potentially grow the operation by investing revenues). The case studies revealed other characteristics of hyperlocals, including details of their content, staffing, and revenue streams. For example, while $32 \%$ of content is focused on politics and public affairs, the outlets also cover culture and the arts (17\%), event listings (15\%), and human-interest stories (12\%), in addition to business, sports, crime, and other topics. The sites have also diversified their revenue sources, with 14 cases relying on five or more revenue streams (three streams was the most common model). The most-used approaches included online display advertising; native advertising, advertorials, and sponsored content; partnerships; grants; print products/ subscriptions; events; and membership models. More than half of the hyperlocals reported that they were sustainable or viable, and even low-income outlets considered themselves sustainable or resilient, although proportionally more sites with higher revenues identified themselves in these ways. Additionally, more diversification did not necessarily mean higher sustainability or resilience, as 12 of these sites featured fewer than four revenue sources. Ultimately, Cook's research showed that in the hyperlocal business ecosystem, news producers are going beyond advertising-driven approaches to diversify their commercial strategies via both formal and informal relationships involving a diversi- ty of actors. They also demonstrate potential for alternative commercial approaches in addition to advertising, such as involving volunteers, developing membership and donation models, hosting community events, and forming relationships with other local publishers and businesses to share skills and resources. These complex entanglements help to explain the diversity of commercial strategies evident among these players, and the asymmetrical ways they have developed, and show that hyperlocals with more relationships are also more sustainable or resilient.

These alternative approaches even work in a small media market such as Switzerland, as the recent success of crowdfunded and now membership-based journalism start-up Republik demonstrates.

\section{Outcomes and reflections}

This panel demonstrated that despite the continuing challenges they face in terms of consolidation and centralization, growing competition from other online information sources, and the need to draw new readers and develop digital-driven monetization models, local media remain diverse, innovative, and democratically vital. Their contributions are particularly important in areas on the periphery, which may experience the effects of economic, political, and technological change even more acutely. The panelists also emphasized the need for continued research on local media, such as efforts to measure content diversity, particularly in highly consolidated media environments; examine the effects of political pressure on local journalists and the different forms it takes, such as funding initiatives; evaluate and classify the effectiveness of various content-monetization strategies; and understand existing and emerging ways local media are working to connect with their audiences and communities. 


\section{Panel overview}

\section{Panel title}

Journalism from the peripheries. From the Swiss-Italian media system to other local dimensions

Panel organizer

Philip Di Salvo (USI Università della Svizzera italiana)

Date and location

Thursday, $1^{\text {st }}$ November 2019, 09:00-10:30

Villa Ciani, Room 015

Are Swiss news media losing their edge? The role of media policy in fostering journalism innovation.

Porlezza, C. (City, University of London, Department of Journalism, London, United Kingdom)

The Swiss media system and its idiosyncrasies.

Hibberd, M. (USI Università della Svizzera italiana, Institute of Media and Journalism (IMeG), Lugano, Switzerland)

The role of public service broadcasting in the Italian speaking part of Switzerland. Herber, M. (RSI Radiotelevisione svizzera, Lugano, Switzerland)

\section{The digital transition of local news.} Jenkins, J. (University of Oxford, Reuters Institute for the Study of Journalism, Oxford, United Kingdom)

Sustaining media on the edge.

Cook, C. (University of Central Lancashire, School of Journalism, Media and Performance, Preston, United Kingdom)

\section{References}

Abernathy, P. (2018). The expanding news desert. UNC School of Media and Journalism. Retrieved from: https://www.usnewsdeserts.com/

Business Daily. (2019, April 16). BBC. Retrieved from: https://www.bbc.co.uk/programmes/w3csy7cz

Cavendish, S. (2019, January 25). Local newspapers have already been gut- ted. There's nothing left to cut. The Washington Post. Retrieved from: https://www.washingtonpost.com/ outlook/local-newspapers-have-already-been-decimated-theres-nothing-left-to-cut/2019/01/25/248fe102200d-11e9-9145-3f74070bbdb9_story. $\mathrm{html}$ ?noredirect $=$ on\&utm_term $=$.fac444ef0a20

Harte, D., Howells, R., \& Williams, A. (2018). Hyperlocal journalism: The decline of local newspapers and the rise of online community news. London and New York: Routledge.

Hayes, D., \& Lawless, J. L. (2018). The decline of local news and its effects: New evidence from longitudinal data. The Journal of Politics, 80(1), 332-336.

Hess, K. (2013). Breaking boundaries: Recasting the "local" newspaper as "geo-social" news in a digital landscape. Digital Journalism, $1(1), 48-63$.

Jenkins, J., \& Graves, L. (2019). Case studies in collaborative local journalism. Oxford: Reuters Institute for the Study of Journalism. Retrieved from: https://reutersinstitute. politics.ox.ac.uk/our-research/casestudies-collaborative-local-journalism

Kurpius, D. D., Metzgar, E., \& Rowley, K. (2010). Sustaining hyperlocal media. Journalism Studies, 11(3), 359-76.

Napoli, P. M., Weber, M., McCullough, K., \& Wang, Q. (2018). Assessing local journalism: News deserts, journalism divides, and the determinants of the robustness of local news. DeWitt Wallace Center for Media \& Democracy, Duke University. Retrieved from: https://dewitt.sanford.duke.edu/ wp-content/uploads/2018/08/Assessing-Local-Journalism_100-Communities. pdf

Nielsen, R. K. (2015). Local newspapers as keystone media: The increased importance of diminished newspapers for local political information environments. In R. K. Nielsen (Ed.), Local journalism: The decline of newspapers and rise of digital media (pp. 51-72). London: I. B. Tauris.

Nygren, G., Leckner, S., \& Tenor, C. (2017). Hyperlocals and legacy media: media ecologies in transition. Nordicom Review, 39(1), 33-49. 
Reader, B., \& Hatcher, J. (2012). Foundations of community journalism. Thousand Oaks: California: Sage.

Stonbely, S. (2017). Comparing models of collaborative journalism. Center for Cooperative Media. Retrieved from: https:// collaborativejournalism.org/models/

Van Kerkhoven, M., \& Bakker, P. (2014). The hyperlocal in practice: Innovation, creativity and diversity. Digital Journalism, 2(3), 296-309.
Waterson, J. (2019, May 7). Read all about it? How local papers' decline is starving communities of news. The Guardian. Retrieved from: https://www.theguardian.com/ uk-news/2019/may/07/read-all-aboutit-how-local-papers-decline-is-starvingcommunities-of-news. 